\title{
Experimental Investigation on the Load Capacity of a Scaffolding Frame
}

\author{
Mitch Gohnert $^{\# 1}$, Kuinian Li, Ki Sang Son ${ }^{* 2}$ \\ ${ }^{\text {\# }}$ TheUniversity of Witwatersland, Johanneburg,South Africa \\ 1 gohnert@wits.ac.za
}

\begin{abstract}
Presented in this paper is an experimental investigation on the load capacity of a scaffolding frame. Effects on load carrying capacity of base jacks, bracing and using of buckled pipes are investigated. Especially, bracing a scaffolding frame with steel wire strand is experimentally studied and the results are compared with that of a frame braced with pipes.
\end{abstract}

Keywords: load capacity, scaffolding, back jack, bracing, buckled pipe

\section{INTRODUCTION}

All over the world, scaffolding frames are used for almost all construction operations to support workers, materials and structural elements or used as shoring. With lives and property relying on scaffolding systems, it should not be an issue that all involved, from the manufacturers of parts, fittings and accessories, erectors and users of scaffolding frames, should have a sound knowledge about the load carrying capacity and factors that could affect the load capacity. However, construction practice relies primarily on experience to determine a particular scaffolding arrangement deemed to safely carry a load. And, in not few cases, people thought that a scaffolding system should be able to carry as much as you put on it. It is common that some parts, fittings and accessories are not installed simply because they are not available or time constraints. Furthermore, parts such as pipes, fittings and accessories for scaffolding systems are almost always reused and sometimes they are in poor conditions. It is inevitable that the formwork will be damaged by earlier use or other related processes such as transportation. The question is, how will this affect the load carrying capacity of a scaffolding system?

If scaffolding collapses, the loss of property and lives is possible. The recent scaffolding collapse at Time Square in New York City [1], the scaffolding collapse at the power plant site outside of Tel Aviv in Israel [2], the scaffolding frame shoring collapse in Seoul, Korea [3] and the collapse of the steel scaffolding support in Taipei, Taiwan [4] have all led to fatalities and have focused the international construction community on the importance of the safe design and erection of scaffolding.

As a result, many manufacturers are accumulating load test data on components of their scaffolding systems. However, it must be clear that such information alone can not provide a direct means of predicting the load carrying capacity of a complete system on a job site.

A few analytical and/or experimental studies on the load carrying capacity of scaffolding systems have been done. Peng et al [4] performed a second order analysis on a two-storey scaffolding frame with two- and threedimensional models. Peng et al [5, 6] also did a non-linear analysis on scaffolding systems. Using ABAQUS, Mroz [7] analyzed perfectly straight shelf scaffolding, without imperfection taken into consideration.

An Experimental study on a large full-scale scaffolding frame subjected to pattern loads with various load paths was performed by Weeser[8]. Weesner [9] also carried out experimental and analytical study on four different types of frame scaffolding systems, using Commercial software ANSYS. Both eigen buckling analysis and non-linear analysis were performed. The analytically predicted ultimate load carrying capacity matches the experimentally observed results well.

Monitoring systems for scaffolding frame shoring systems have also being developed [10]. Such a system is aimed to monitor the state of a scaffolding frame and issue warning signals in advance of its collapse.

To observe the effect of various conditions on the load capacity and failure of a scaffolding frame, experimental investigations on five scaffolding frames were performed. The five scaffolding frames are: A scaffolding frame without base jack, a scaffolding frame without bracing, a scaffolding frame with buckled components, a scaffolding frame braced with steel wire strand and a standard scaffolding frame—a scaffolding 
frame with base jack, using no damaged or buckled components and braced with pipes. The effects of base jacks, buckled components and different bracings on the load carrying capacity and failure mode of a scaffolding frame are discussed.

\section{METHOD}

Five different varieties of frame scaffolding were tested in the work reported herein. All the scaffolding frames are constructed with steel pipes which are widely used at construction sites. The size and material properties of the pipes are presented in Table 1 and the sizes of the connections and base plates are given in Table 2. A standard scaffolding frame with tubular x-bracing (named frame A as shown in Figure 1) is tested in comparison with the other four scaffolding frames: Frame B- a scaffolding frame without bracing, as shown in Figure 2, Frame C- a scaffolding frame without bracing, without base jack, as shown in Figure 3; Frame D- a scaffolding frame with buckled pipe component incorporated in the frame, as shown in Figure 4, and frame Ea scaffolding frame with steel wire strand bracing, as shown in Figure 5.

Table 1. Size and mechanical properties of pipes

\begin{tabular}{|c|c|c|c|c|}
\hline $\begin{array}{c}\text { Inner Diameter } \\
(\mathrm{mm})\end{array}$ & $\begin{array}{c}\text { Outer Diameter } \\
(\mathrm{mm})\end{array}$ & $\begin{array}{c}\text { Moment of } \\
\text { inertia }\left(\mathrm{mm}^{4}\right)\end{array}$ & $\begin{array}{c}\text { Yielding stress } \\
(\mathrm{MPa})\end{array}$ & $\begin{array}{c}\text { Tensile strength } \\
(\mathrm{MPa})\end{array}$ \\
\hline 44 & 48.6 & 89867 & 353 & 500 \\
\hline
\end{tabular}

Table 2. Sizes of connections and base plates

\begin{tabular}{|c|c|c|}
\hline Connections & $50 \times 50 \mathrm{~mm}$ & \\
\hline Base plates & $120 \times 120 \times 5 \mathrm{~mm}$ & \\
\hline
\end{tabular}

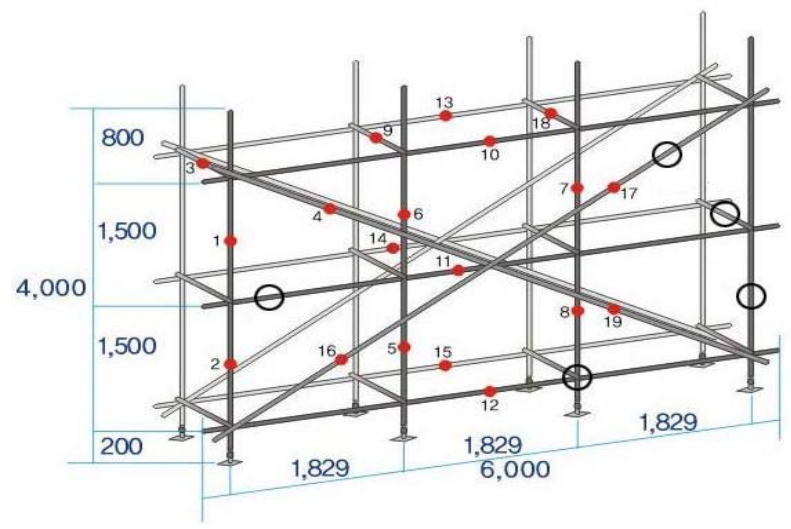

Fig.1. Frame A— a standard scaffolding frame with tubular x-bracing 


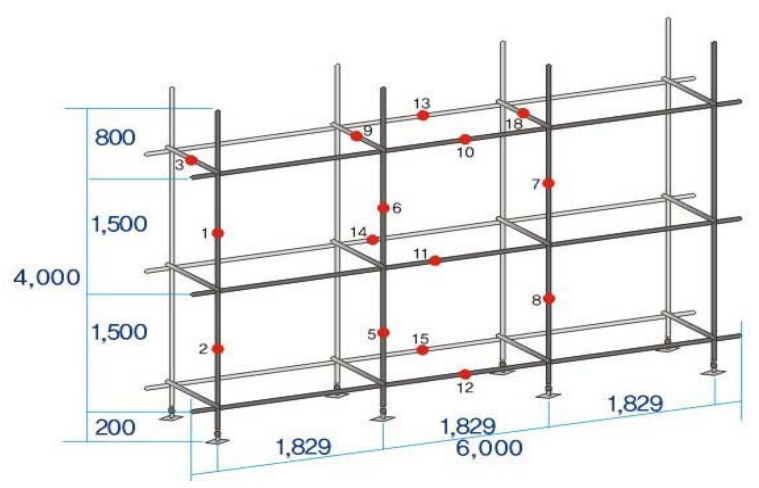

Fig.2. Frame B- a scaffolding frame without bracing

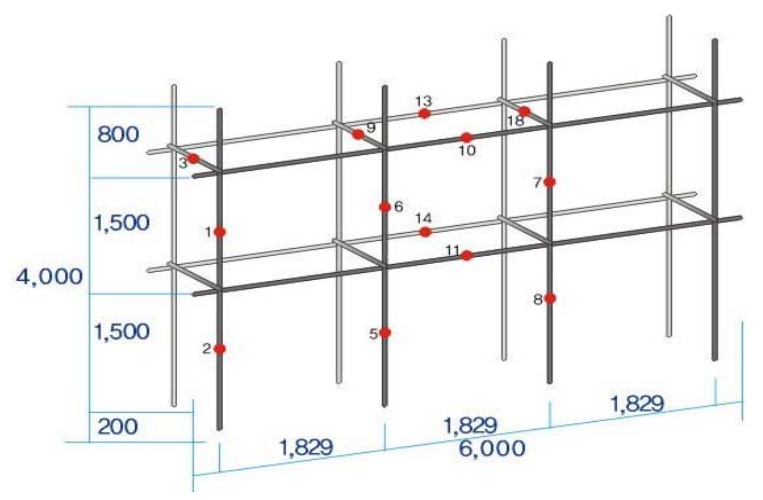

Fig.3. Frame C—a scaffolding frame without bracing and without base jacks

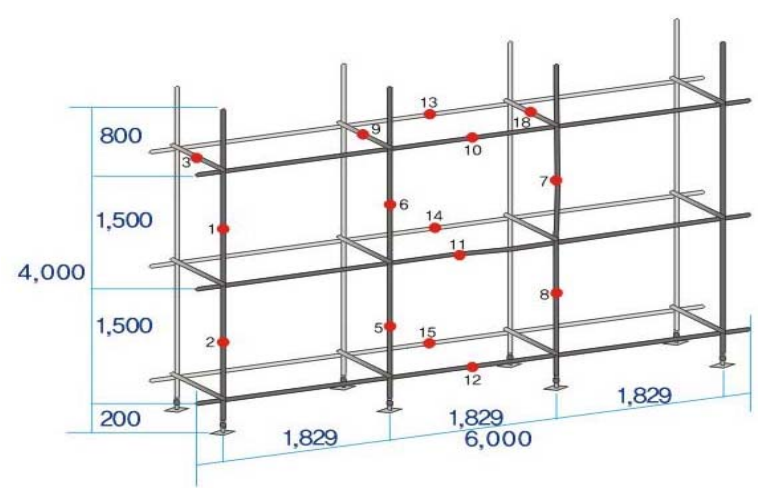

Fig.4. Frame D— a scaffolding frame without bracing and with a buckled pipe incorporated in the frame

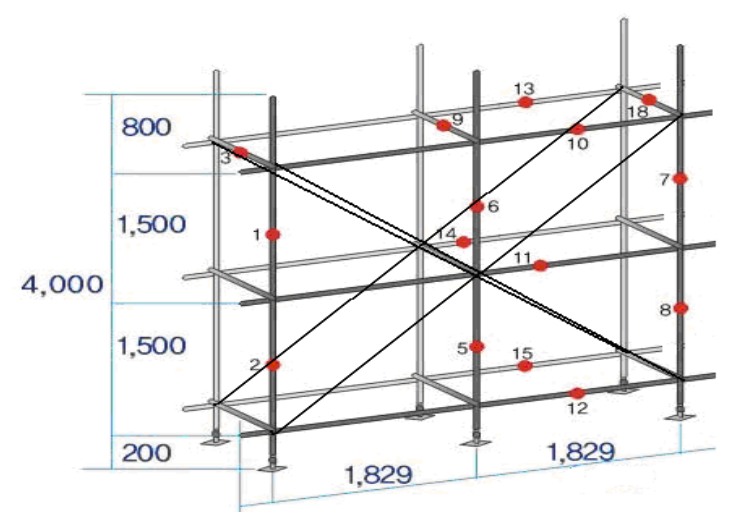

Fig.5. Frame E—a scaffolding frame with steel wire strand bracing 
Figure 6 presents the sketch and photo of the end-view of the scaffolding testing assembly. Load was applied to the system through the loading beams placed on the top of the frame. A pneumatic ram produces and exerts force on the center of the loading beam system by reacting against a loading frame erected over the scaffolding assembly. The load exerted was monitored by recording the pressure in the ram and by a load cell. Strain gauges are placed at key points in frame A -E, as shown in Figure 7. Two LVDT and 9 dial gauges are attached to the frames to monitor the displacements, in and out of plane. The test set-up is shown in Figure 8. An automated data acquisition system was employed to record the load, strains and displacements. In each test, the loading was increase until the assembly failed.

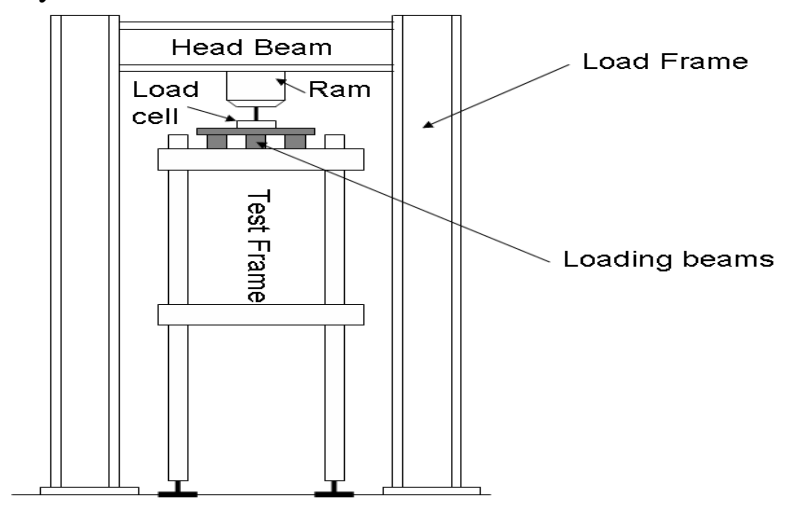

Fig.6. End view of scaffolding frame testing assembly
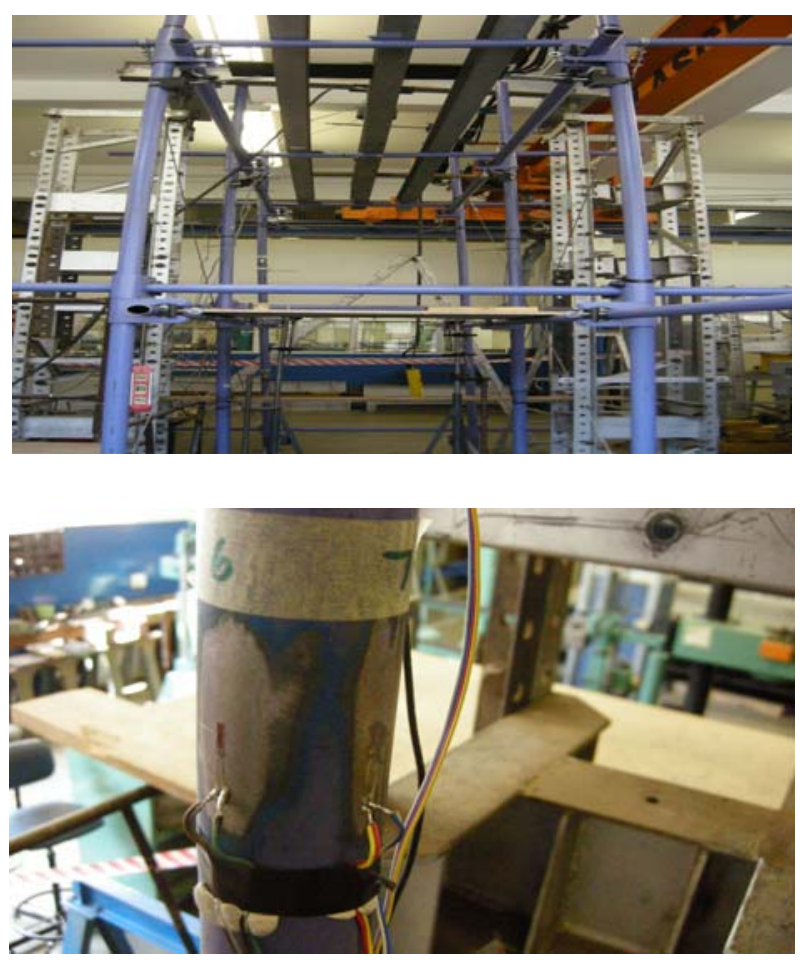

Fig.7. strains in and out of plane at key points are monitored on-line 


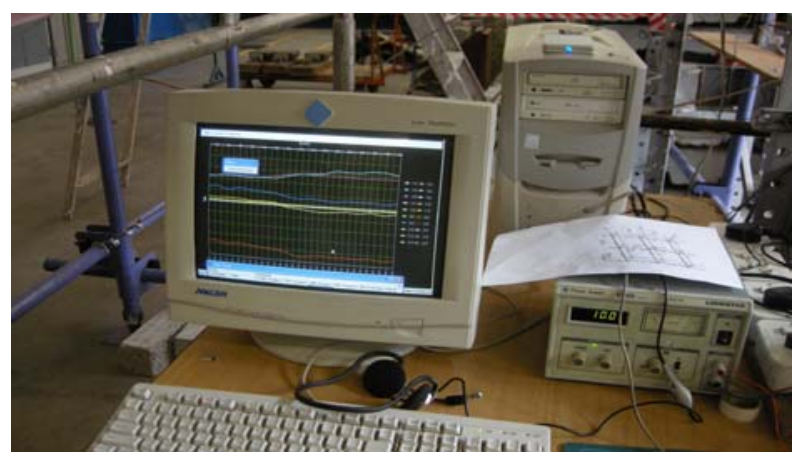

Fig.8. The test set-up

III.RESULTS

Table 2 lists the test data for each of the tests.

Table 2. Buckling load of different frames

\begin{tabular}{|c|c|c|c|c|}
\hline Frame & $\begin{array}{c}\text { Total } \\
\text { load at } \\
\text { failure(kN) }\end{array}$ & $\begin{array}{c}\text { Sway (Hori- } \\
\text { zontal) (mm) }\end{array}$ & $\begin{array}{c}\text { Maximum } \\
\text { vertical } \\
\text { displacement } \\
\text { (mm) }\end{array}$ & Mode of failure \\
\hline $\begin{array}{c}\text { Frame A: } \\
\text { standard } \\
\text { scaffolding } \\
\text { frame with } \\
\text { tubular } \\
\text { x-bracing }\end{array}$ & 78.99 & 5 & 21.96 & $\begin{array}{c}\text { As shown in Figure 9, the sway is very small. } \\
\text { The failure is resulted from buckling. }\end{array}$ \\
\hline $\begin{array}{c}\text { Frame B: } \\
\text { scaffolding } \\
\text { frame without } \\
\text { bracing }\end{array}$ & 48.22 & 35 & 25.12 & $\begin{array}{c}\text { As shown in Figure 10, the in-plane sway is } \\
\text { very big, though the out-plane sway is not } \\
\text { serious. The big sway decreased the load } \\
\text { capacity and speeded buckling of the frame }\end{array}$ \\
\hline $\begin{array}{c}\text { Frame C: } \\
\text { scaffolding } \\
\text { frame without } \\
\text { bracing, } \\
\text { without base } \\
\text { jack }\end{array}$ & 40.08 & 43 & 29.37 & $\begin{array}{c}\text { As shown in Figure 11, both in-plane and } \\
\text { out-plane sway are very big, frame failed due } \\
\text { to buckling at very low load. }\end{array}$ \\
\hline $\begin{array}{c}\text { Frame D: } \\
\text { scaffolding } \\
\text { frame without } \\
\text { bracing, with } \\
\text { buckled pipe }\end{array}$ & 41.94 & 40 & 34.72 & $\begin{array}{c}\text { As shown in figure 12, both in-plane and } \\
\text { out-plane sway are serious. Failure due to } \\
\text { buckling occur at very low loading }\end{array}$ \\
\hline $\begin{array}{c}\text { Frame E: } \\
\text { scaffolding } \\
\text { frame with steel } \\
\text { wire strand } \\
\text { bracing }\end{array}$ & 49.70 & 12 & 34.50 & $\begin{array}{c}\text { As shown in Figure 13: sways both in-plane } \\
\text { and out-plane are very small but the } \\
\text { connection sliding is significant, which } \\
\text { affected the further increasing of load }\end{array}$ \\
\hline
\end{tabular}




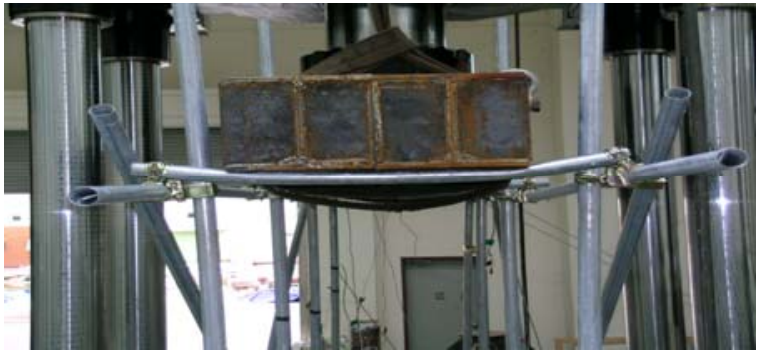

Fig.9. Failing of Frame A: standard scaffolding frame with tubular x-bracing

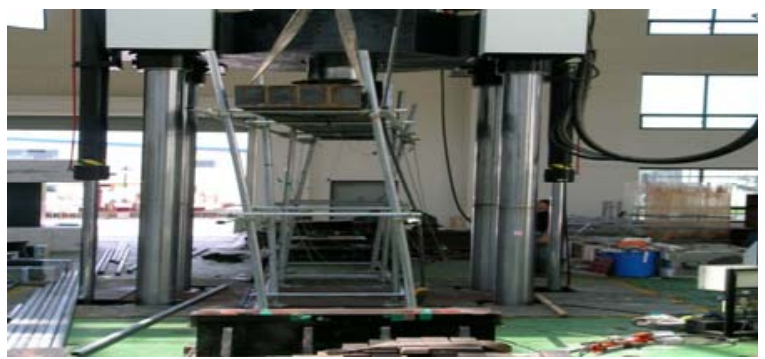

Fig.10. Failing of frame B: scaffolding frame without bracing

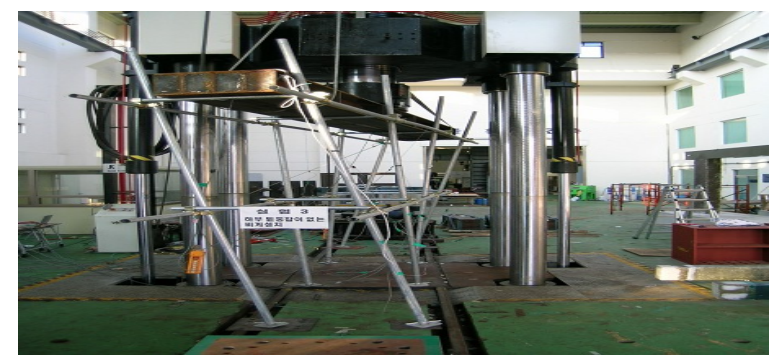

Fig.11. Failing of frame C: scaffolding frame without bracing, without base jack

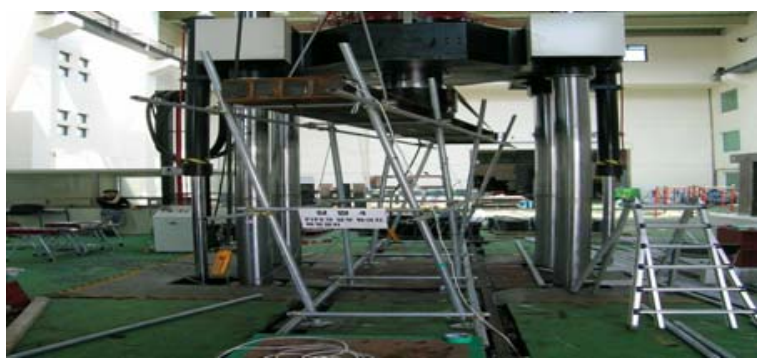

Fig.12. Failing of frame D: scaffolding frame without bracing, with buckled pipe

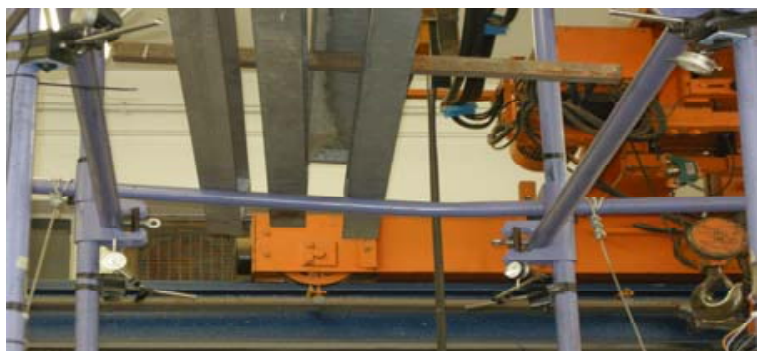

Fig.13. Failing of frame E: scaffolding frame with steel wire strand bracing 


\section{IV.ANALYSIS}

From Table 2 it can be seen that the total buckling load of the scaffolding frame without bracing (Frame B) is about $61 \%$ of that of the standard frame (Frame A). This shows that missing of bracing could lead to significant loss of load capacity of a scaffolding frame. On the other hand, the sway displacement of the scaffolding frame without bracing is much bigger than that of that of the standard scaffolding frame.

If the base jacks are missing (Frame C), it can be seen that the load capacity will be further reduced to about $51 \%$ compared to the standard scaffolding frame. In this test, the sways both in-plane and out-plane increased significantly. Comparing the failure of Frame B and that of Frame C, it can be found that the out-plane sway of Frame $\mathrm{C}$ is much bigger than that of Frame B. This difference should come from the missing of base jack. The tests indicate that the function of base jacks is not negligible and they will affect the load capacity if the scaffolding frame if omitted.

As mentioned, it is common practice to reuse components of scaffolding frames, such as pipes and other accessories. However, if a buckled pipe is used in a scaffolding frame, the load bearing capacity of the scaffolding frame could be significantly affected. This is illustrated in the test results shown in Table 2. It can be seen that the total buckling load of Frame D, scaffolding frame without bracing, with a buckled pipe, is about $53 \%$ of the standard scaffolding frame, Frame A. Compared with frame B, using of a buckled pipe led to a further $13 \%$ decrease in load capacity.

The test on using steel wire strand as bracing produces promising results as an alternative method of stabilizing a frame. As shown in Frame E, the scaffolding frame braced with steel wire strand is a two-bay frame. It can be seen that the total buckling load of frame $E$ is very close to 2/3 of the buckling load of the standard scaffolding frame, Frame A, which is three-bay frame X-braced with tubular pipes. This means the load capacity of frame $\mathrm{E}$ is very close to that of frame A. It should be noticed that the vertical displacement of Frame $\mathrm{E}$ is big, due to the sliding of the connections. This problem needs to be solved if steel wire strand is to be used for bracing. The sway of Frame $\mathrm{E}$ is not big. If the sliding of the connections can be prevented and the adding load can be more evenly distributed on the frame, the buckling load could be further increased.

The steel wire strand can is flexible, therefore, it is possible to use a single steel wire strand to brace the scaffolding frame, even in different directions and planes, and thus improve the integrity and stability of the scaffolding frames. This will be investigated by the following tests.

\section{CONCLUSION}

Bracing of scaffolding frame is absolutely necessary, even for a temporary using scaffolding frame. Missing of bracing could not only lead to significant reducing of load capacity but sudden and disastrous collapsing of the frame due to large sway and little restraining on the sway. The base jack of a scaffolding frame, even though its size is negligibly small compare to that of a large frame, could affect the load capacity of a scaffolding frame seriously. Missing of base jack could reduce the load capacity obviously. More importantly, missing of base jack could lead to significant out-plane sway and sudden collapsing of the frame. Even though it is common in practice that pipes and other components of scaffolding frames are reused, involving of buckled pipe could sacrifice the load capacity and led to sudden collapsing of the frame. As an alternative approaching of stabilizing frames, bracing with steel wire strand gives promising results, though further tests need to be performed.

\section{ACKNOWLEDGEMENT}

This research has been made with a partial support of the university of Witwatersland,South Africa.

\section{REFERENCE}

[1] Rentschler G.P, Walkup S, The time square scaffold collapse, Forensic Engineering, 2000, P75-84

[2] Ayyub BM, Eldukair ZA, Impact of errors on safety during construction, Proceedings of the Sessions Related to Design, Analysis and Testing, ASCE Structures Cogress, ’89, San Francisco, CA,1989:835-843

[3] Ki-San Son, Recent cases of serious construction accidents in Republic of Korea, technical report, 2008, Seoul National University of Technology

[4] Yen T, Lin, et al, Research of steel scaffolding accidents during construction period, labor checking report, the council of labor affairs, Taipei, Taiwan, 1993 [in Chinese] 
[5] JL Peng, et al, High clearance scaffolding systems during construction - structural modeling and modes of failure, Engineering Structures,1996:18(3):247-257

[6] JL Peng, et al, High clearance scaffolding systems during construction — structural analysis and development of design guidelines, Engineering Structures,1996:18(3):258-267

[7] K Gylltoft, K Mroz, Load-carrying capacity of scaffolds, Structural Engineering, 1995; 5(1)37-42

[8] JL Peng, et al, Performance of scaffold frame shoring under pattern loads and load paths, Journal of Construction Engineering and Management, 1997, Vol123 pp:138-145

[9] L.B. Weesnr, H.L. Jones, Experimental and analytical capacity of frame scaffolding, Engineering Structures, 2001, 23:592-599

[10] Y.L Hung et al, A monitoring method for scaffolding frame shoring system for elevated concrete framework, Computers \& Structures, 2000, 78:681-690 